\title{
Relationship satisfaction in lesbian and heterosexual couples before and after assisted reproduction: a longitudinal follow-up study
}

\author{
Catrin Borneskog $^{1 *}$, Claudia Lampic ${ }^{2}$, Gunilla Sydsj ${ }^{3,4}$, Marie Bladh $^{3,4}$ and Agneta Skoog Svanberg ${ }^{1}$
}

\begin{abstract}
Background: More and more lesbian couples are planning parenthood through donor insemination and IVF and the number of planned lesbian families is growing in Sweden and other western countries. Research has shown that lesbian couples report as much overall satisfaction in their relationships as do heterosexual couples. However, although parenthood is highly desired, many parents are unaware of the demands of parenthood and the strain on their relationship that the arrival of the baby might bring. The aim of this study was to compare lesbian and heterosexual couples perceptions of relationship satisfaction at a three-year follow up after assisted reproduction.

Methods: The present study is a part of the Swedish study on gamete donation, a prospective longitudinal cohort study. The present study constitutes a three-year follow up assessment of lesbian and heterosexual couples after assisted reproduction. Participants requesting assisted reproduction at all fertility clinics performing gamete donation in Sweden, were recruited consecutively during 2005 2008. A total of 114 lesbian women (57 treated women and 57 partners) and 126 heterosexual women and men (63 women and 63 men) participated. Participants responded to the ENRICH inventory at two time points during 2005 2011; at the commencement of treatment (time point 1) and about three years after treatment termination (time point 3). To evaluate the bivariate relationships between the groups (heterosexual and lesbian) and socio-demographic factors Pearson s Chi- square test was used. Kolmogorov-Smirnov test was used for testing of normality, Mann Whitney U- test to examine differences in ENRICH between the groups and paired samples t-test to examine scores over time.
\end{abstract}

Results: Lesbian couples reported higher relationship satisfaction than heterosexual couples, however the heterosexual couples satisfaction with relationship quality was not low. Both lesbian and heterosexual couples would be classified accordingly to ENRICH-typology as vitalized or harmonious couples.

Conclusions: At a follow-up after assisted reproduction with donated sperm, lesbian couples reported stable relationships and a high satisfaction with their relationships, even when treatment was unsuccessful.

Keywords: Relationship satisfaction, Lesbian couples, Sperm donation

\section{Background}

Research into factors that influence intimate romantic relationships has previously been mainly conducted on heterosexual couples. However, the research body on relationships in same-sex couples is increasing. In general it seems that aspects that influence heterosexual relationships also influence same-sex relationships. For

\footnotetext{
* Correspondence: catrin.borneskog@kbh.uu.se

'Department of Women s and Children s Health, Uppsala University, S-751 85 Uppsala, Sweden

Full list of author information is available at the end of the article
}

example, in a review of empirical studies of same-sex couples in the United States, it was suggested that the similarities between same-sex and heterosexual couples far outweigh the differences, both in relationship quality and the processes that regulate satisfaction and commitment [1].

During the last decades in Sweden, there have been a series of societal changes in order to provide people with the same rights and opportunities regardless of sexual orientation. In 2003, adoption of children was opened up to same-sex couples; in July 2005 assisted reproduction 
with donated sperm become available to lesbian couples within the Swedish public health care system; and in 2009 the gender-neutral legislation about same-sex marriage was introduced (SFS 2009:260) [2].

The desire to have children is the same to all individuals. To some the desire is very strong, to some it is weaker. Like heterosexual women, many lesbian women have a strong desire for parenthood and want children [3-5]. A planned lesbian family is when two women have opted for motherhood within a lesbian relationship. However, planned lesbian families differ from lesbian families with children originating from heterosexual relationships [6,7]. In the former families the parental composition has changed, and parent and child have experienced divorce and the coming out of the mother [6,7].

The transition to parenthood is the time and psychological process people and couples undergo during pregnancy and the first months after birth; a psychological process changing women and men into parents. According to Lewis [8], who describes the transition to parenthood, it seems that relationships which function well before pregnancy and birth remain good during the babys first year. Relationships where the spouses have problems with communication and emotional intimacy seem to be more vulnerable with regard to parenthood [8]. In a study from Sweden of first-time parents experiences of their intimate relationship it was found that, although parenthood is highly desired by the couples, they are unaware of and not prepared for the demands of parenthood and the strain on their relationship that the arrival of the new baby can bring [9].

Research has shown that lesbian couples report as much overall satisfaction in their relationships as do heterosexual couples [10]. Higher educational level of lesbian individuals and the fact that lesbian couples are less likely to have previous children are factors suggested to impact positively on lesbian couples relationships $[11,12]$.

Previously we have reported a high relationship satisfaction in lesbian couples [13]. We also found that relationship satisfaction in lesbian women with previous children was lower than it was in lesbian women without previous children.

Donor insemination in lesbian couples [14-16] and fertility treatments $[17,18]$ are known to be stressful and influence on the quality of life of the couples in all kinds of ART. Psychosocial wellbeing, sexual satisfaction and marital relationship are aspects mentioned as being impaired by fertility treatment [17,19-23]. Further, a decrease in relationship satisfaction may affect the transition to parenthood for couples undergoing fertility treatment [24]. The couples relationship during the first year of parenting is particularly vulnerable and many divorces take place during this time [9].
Lesbian couples starting a family through sperm donation treatment are a new and growing [13] group of patients in obstetric and neonatal/paediatric care in Sweden. However, little is known about the intimate romantic relationship of lesbian couples planning a family with children. Unique to lesbian couples is the fact that they are two women planning a family together where one of the parents will not have a biogenetic link to the offspring. Additionally, lesbian couples are a largely stigmatized group and have previously been (unfairly) depicted as having many psychosocial problems $[25,26]$.

The aim of this study was to study lesbian couples satisfaction with their relationship at a three year follow-up after assisted reproduction treatment and to relate these findings to pre-treatment perceptions of the relationship and demographic variables. Another aim was to compare these variables with a group of heterosexual couples undergoing IVF-treatment with their own gametes during the same treatment course.

The following specific research questions were posed:

1. How do the perceptions of relationship satisfaction between lesbian and heterosexual couples at three-year follow-up differ compared to their perceptions of the relationship before treatment?

2. Are the perceptions of lesbian and heterosexual couples relationship satisfaction related to demographic variables such as age, level of education and being the treated women or the partner?

3. Are the perceptions of lesbian and heterosexual couples relationship satisfaction related to a successful outcome of the treatment?

\section{Methods}

The Swedish study on gamete donation is a prospective longitudinal study aiming to investigate the psychosocial and medical aspects of donor conception. The multicentre study includes both donors and recipients of donated gametes, as well as a comparison group of heterosexual couples using IVF-treatment with their own gametes. Participants were recruited from all fertility clinics performing gamete donation in Sweden i.e. University hospitals in Stockholm, Gteborg, Uppsala, Ume, Linkping, rebro and Malm.

During 2005 2008, a consecutive cohort of lesbian ART (assisted reproduction treatment) couples at the commencement of sperm donation treatment, were approached for participation. For comparison, heterosexual couples that started standard IVF-treatment with their own gametes at four of the participating fertility clinics were asked to participate in the study. Inclusion criteria were: being able to read and understand Swedish well enough to answer the questionnaire. The longitudinal 
study consisted of data collection at three time points; at the commencement of treatment (T1), two months after treatment (T2) and about three years after treatment (T3) when a potential child was between 1236 months old.

The questionnaires at this presentation were distributed by mail together with a prepaid return envelope and a cover letter stating the purpose of the study and guaranteeing confidentiality. The partners in the couples received one questionnaire each. The couples were asked to complete the questionnaire individually. Two reminders to non-responders were sent.

Of a consecutive cohort of 214 lesbian couples (428 individuals) about to receive donor insemination and 212 heterosexual couples (424 individuals) starting regular IVF treatment with their own gametes, 166 lesbian couples (78\% response) and 151 heterosexual couples (71\% response) accepted participation in the study (T1).

Since one aim of this study was to investigate changes over time in couples relationship satisfaction before and after assisted reproduction, only couples that responded to questionnaires at commencement of treatment (T1) and about three years after treatment (T3) were included. Of the eligible couples, 57 lesbian (57 treated women and 57 partners) and 63 heterosexual (63 women and 63 men) couples participated in this study and responded to the questionnaire. Figure 1 displays a detailed description of participants.

Previous studies have shown that the similarities between lesbian and heterosexual couples far outweigh the differences [1,27]. The lesbian and heterosexual couples turn to assisted reproduction due to a strong desire to conceive and to have children. Before being accepted for assisted reproduction the couples undergo a psychosocial investigation and consequently, the couples in this study are psychologically healthy. It is reasonable to believe that, although different in nature, the experiences of distress related to both medical and social infertility influence psychological wellbeing. In addition, in this sample, $65 \%$ of the lesbian women also underwent IVFtreatment and it is likely that the hardship of IVFtreatment and hormone stimulation are similar to both lesbian and heterosexual women. These aspects of similarities provide a solid foundation for comparisons of changes in relationship satisfaction during a time of assisted reproduction between lesbian and heterosexual couples.

Table 1 displays the demographic data. There were no differences in age between participants (lesbian vs. heterosexual treated women $\mathrm{p}=0.622$; lesbian partners vs. heterosexual men $\mathrm{p}=0.193$ ); the majority were older
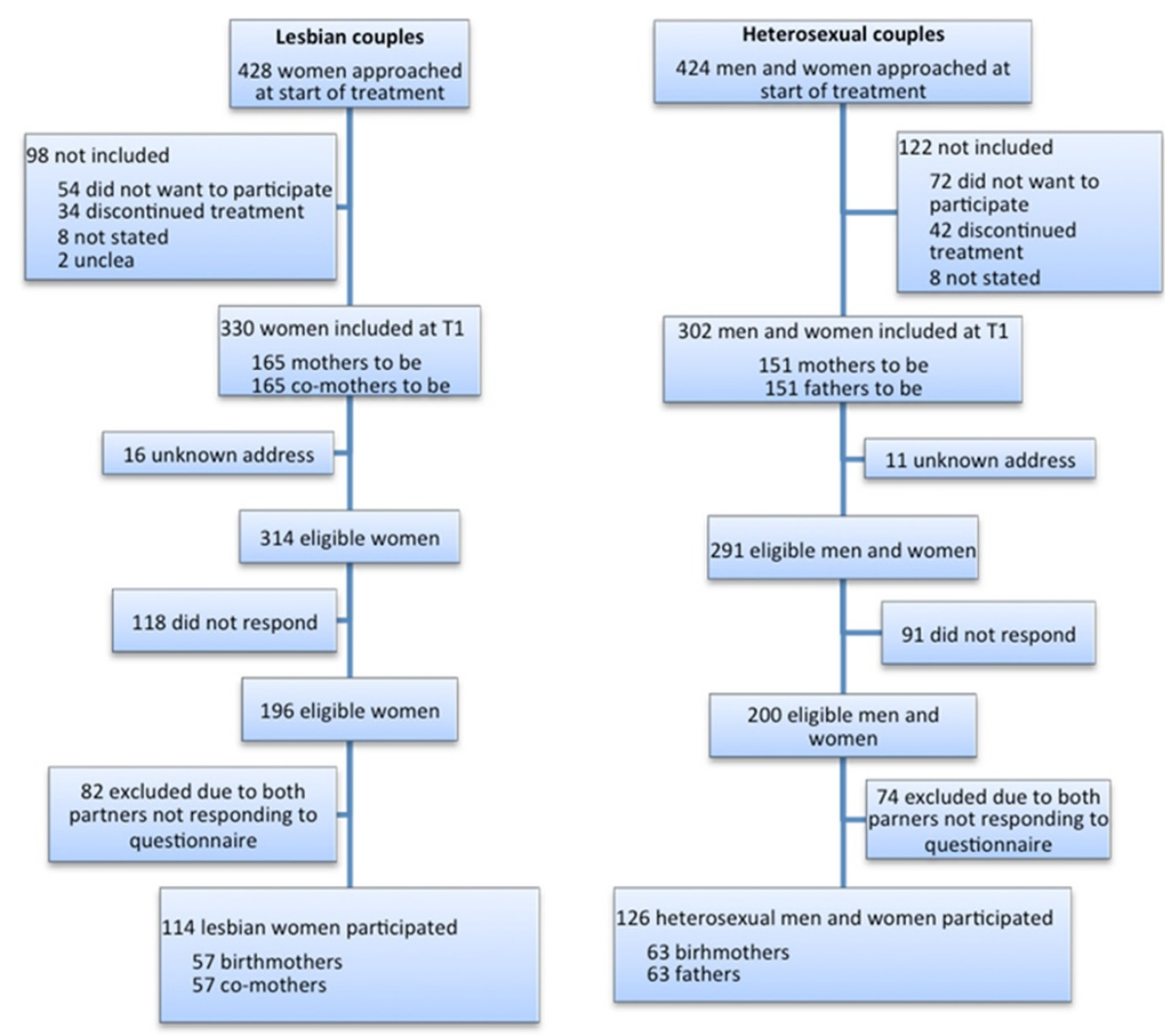

Figure 1 Flow chart over participants and drop-outs. 
Table 1 Demographic data for women and men participating in the study

\begin{tabular}{|c|c|c|c|c|c|c|}
\hline & \multicolumn{2}{|c|}{ Hetero } & \multicolumn{2}{|c|}{ Lesbian } & \multirow[b]{2}{*}{ p-value } \\
\hline & & $\bar{n}$ & $\%$ & $n$ & $\%$ & \\
\hline \multicolumn{7}{|l|}{ Mother } \\
\hline \multirow[t]{2}{*}{ Age } & $\leq 30$ & 22 & 34.9 & 22 & 39.3 & 0.622 \\
\hline & $>30$ & 41 & 65.1 & 34 & 60.7 & \\
\hline \multirow[t]{3}{*}{ Education } & Elementary & 0 & 0.0 & 1 & 1.8 & 0.375 \\
\hline & High school & 23 & 36.5 & 16 & 28.1 & \\
\hline & University & 40 & 63.5 & 40 & 70.2 & \\
\hline \multirow[t]{2}{*}{ Biological children } & No & 55 & 100.0 & 53 & 94.6 & 0.243 \\
\hline & Yes & 0 & 0.0 & 3 & 5.4 & \\
\hline \multirow[t]{2}{*}{ Adoptive children } & No & 63 & 100.0 & 55 & 96.5 & 0.224 \\
\hline & Yes & 0 & 0.0 & 2 & 3.5 & \\
\hline \multirow[t]{2}{*}{ Step children } & No & 62 & 98.4 & 55 & 96.5 & 0.622 \\
\hline & Yes & 41 & 65.1 & 34 & 60.7 & \\
\hline \multirow[t]{2}{*}{ Child after treatment } & No & 30 & 47.6 & 17 & 29.8 & 0.046 \\
\hline & Yes & 33 & 52.4 & 40 & 70.2 & \\
\hline \multicolumn{7}{|l|}{ Co-mother/father } \\
\hline \multirow[t]{2}{*}{ Age } & $\leq 30$ & 15 & 24.2 & 20 & 35.1 & 0.193 \\
\hline & $>30$ & 47 & 75.8 & 37 & 64.7 & \\
\hline \multirow[t]{3}{*}{ Education } & Elementary & 4 & 6.6 & 1 & 1.8 & 0.227 \\
\hline & High school & 29 & 47.5 & 22 & 39.3 & \\
\hline & University & 28 & 45.9 & 33 & 58.9 & \\
\hline \multirow[t]{2}{*}{ Biological children } & No & 57 & 100.0 & 52 & 92.9 & 0.057 \\
\hline & Yes & 0 & 0.0 & 4 & 7.1 & \\
\hline \multirow[t]{2}{*}{ Adoptive children } & No & 63 & 100.0 & 57 & 100.0 & - \\
\hline & Yes & & & & & \\
\hline \multirow[t]{2}{*}{ Step children } & No & 59 & 93.7 & 57 & 100.0 & 0.121 \\
\hline & Yes & 4 & 6.3 & 0 & 0.0 & \\
\hline \multirow[t]{2}{*}{ Child after treatment } & No & 30 & 47.6 & 17 & 29.8 & 0.046 \\
\hline & Yes & 33 & 52.4 & 40 & 70.2 & \\
\hline
\end{tabular}

*Pearson s Chi-square test. If cell count is below 5 Fisher s exact test is used.

than 30 years. Of treated women, $60 \%$ of lesbian and $65 \%$ of heterosexual were more than 30 years old. Of lesbian partners, $65 \%$ were older than 30 years and the corresponding age for heterosexual men was $76 \%$.

There were no differences in educational level between the couples.

Amongst the lesbian couples, 3 treated women and 4 partners had previous biological children; in the heterosexual couples there were no previous biological children.

More lesbian (70.2\%) than heterosexual (52.4\%) couples had had a successful assisted reproductive treatment resulting in the birth of a child $(\mathrm{p}=0.046)$, see Table 1 .

Satisfaction with relationship was assessed with the ENRICH inventory (Evaluating and Nurturing Relationship
Issues, Communication and Happiness). Partner s perception of relationship satisfaction is assessed in 10 dimensions each containing 10 items.

The scales are briefly described as follows:

- Personal issues: Examines an individuals satisfaction with his or her partner s behaviours.

- Communication: Is concerned with an individual s feelings and attitudes towards communication in the relationship. Items focus on the level of comfort felt by the respondent in sharing and receiving emotional and cognitive information from the partner.

- Conflict resolution: Assesses the partner s perception of the existence and resolution of conflict in the relationship. Items focus on how openly issues are recognised and resolved, as well as the strategies used to end arguments.

- Financial management: Focuses on the attitudes and concerns about the way economic issues are managed within the marriage/relationship. Items assess spending patterns and the manner in which financial decisions are made.

- Leisure activities: Assesses preferences for spending free time. Items reflect social versus personal activities, shared versus individual preferences, and expectations about spending leisure time as a couple.

- Sexual relationship: Examines the partner s feelings about the affection and sexual relationship. Items reflect attitudes about sexual issues, sexual behaviour, and sexual fidelity.

- Children and parenting: Assesses attitudes and feelings about having and raising children. Items focus on decisions regarding discipline, goals for the children, and the impact of children in the couples relationship.

- Family and friends: Assesses feelings and concerns about relationships with relatives, in-laws, and friends. Items reflect expectations for and comfort with spending time with family and friends.

- Egalitarian roles: Focuses on an individual s feelings and attitudes about various marital and family roles. Items reflect occupational, household, sex, and parental roles. High scores indicate a preference for more egalitarian roles.

- Conception of life: Examines the meaning of values, religious beliefs and practice, and conception of life within the marriage/relationship.

The Swedish version of this scale, originally created by Olson and co-workers [28] has been evaluated [29] and shown to be reliable and valid. Scores vary between 1 and 5 , with higher scores indicating a better relationship. 
The scale has been used in long-term follow-up of IVF-couples and has been found to be a valid and reliable instrument to measure relationship satisfaction in clinical samples of couples requesting assisted reproduction [21-23].

The ENRICH inventory also assesses Positive Couples Agreement (PCA). Positive Couple Agreement is a measure of the couples congruence on each of the 10 dimensions. The partners responses are combined and the items that they agree on (within 1 point on a 15 scale) are summed and converted to a percentage score, which could range from 0 to $100 \%$.

In 1993, Olson and Fowers [30] conducted an empirical typology based on ENRICH. 6267 couples participated. The study resulted in the identification of five distinct types of married couples. Vitalised couples reported high relationship quality in all subareas. Harmonious couples had relatively high relationship quality. Traditional couples had scores that were slightly above average with markedly higher scores on parenting and religious scales. Conflicted couples were characterised by moderately low scores on all but the role scale. The devitalised couples had the lowest scores on every EN$\mathrm{RICH}$ dimensions. The study did not report any mean values or cut-of scores for the different types of couples, however, the range reported for vitalised couples were mean 64.882 .3 and for harmonious couples mean 42.164 .8 .

Initial analysis of the data included Pearsons chi-square to evaluate the bivariate relationships between group (heterosexual and lesbian) and socio-demographic factors. The ENRICH scores (i.e. the ten factors as well as the total scores on both occasions) for the study group were tested for normality by use of the Kolmogorov-Smirnov test. As the assumption of normality could not be met in all of the studied variables, we chose to primarily use a nonparametric approach when analyzing the data. The Mann Whitney $U$ test was used to examine differences in ENRICH scores between the two study groups, as well as subgroups, while paired samples t-test was used to examine scores over time.

\section{Details of ethical approval}

The study was designed according to the Helsinki declaration. On the 23 of February 2005, the Regional Ethical Review board in Linkping, Sweden approved the study, Dnr: M 2905.

\section{Results}

Tables 2 and 3 display results from the ENRICH assessment at commencement of treatment (T1) and at follow-up (T3). At T1, in general, lesbian couples reported better relationship satisfaction than heterosexual couples. The overall satisfaction with relationship quality decreased in both lesbian and heterosexual couples between T1 and T3. For treated lesbian women the results displayed a decrease in relationship satisfaction in all the ENRICH subareas except for Sexual Relationship and Family and Friends. The lesbian partners also displayed an overall decrease with exception for the subareas Sexual Relationship and Financial Management, Table 4.

In the heterosexual couples, women displayed a decrease in relationship satisfaction in the subareas Personality, Children, Family and Friends, Egalitarian Roles, Conception of Life, Conflict Resolution, Leisure Activities and Total ENRICH. Heterosexual men experienced a decrease in subareas Children, Egalitarian Roles, Conception of Life, Conflict resolution and Total ENRICH compared to T1, Table 4.

Table 2 The couples assessment of their relationship at acceptance for assisted reproduction

\begin{tabular}{|c|c|c|c|c|c|c|c|c|c|}
\hline & \multicolumn{3}{|c|}{ Heterosexual } & \multicolumn{3}{|l|}{ Lesbian } & \multicolumn{3}{|c|}{ Heterosexual vs.Lesbian* } \\
\hline & $\begin{array}{l}\text { Mother } \\
\text { mean/SD }\end{array}$ & $\begin{array}{l}\text { Father } \\
\text { mean/SD }\end{array}$ & $\begin{array}{l}\text { All } \\
\text { Mean/SD }\end{array}$ & $\begin{array}{l}\text { Mother } \\
\text { mean/SD }\end{array}$ & $\begin{array}{l}\text { Co-mother } \\
\text { mean/SD }\end{array}$ & $\begin{array}{l}\text { All } \\
\text { Mean/SD }\end{array}$ & $\begin{array}{l}\text { Mother } \\
\text { p-value }\end{array}$ & $\begin{array}{l}\text { Co-mother/father } \\
\text { p-value }\end{array}$ & $\begin{array}{l}\text { all } \\
\text { p-value }\end{array}$ \\
\hline Personality & $43.8 / 4.5$ & $41.9 / 4.8$ & $42.9 / 4.7$ & $44.7 / 4.4$ & $45.1 / 3.7$ & $44.9 / 4.0$ & 0.169 & $<0.001$ & $<0.001$ \\
\hline Sexual & $43.0 / 3.3$ & $42.8 / 3.6$ & $42.9 / 3.4$ & $44.0 / 2.9$ & $44.2 / 2.9$ & $44.1 / 2.9$ & 0.004 & $<0.001$ & $<0.001$ \\
\hline Children & $43.6 / 3.7$ & $43.9 / 3.4$ & $43.8 / 3.6$ & $44.7 / 2.6$ & $44.5 / 2.7$ & $44.6 / 2.6$ & 0.029 & 0.004 & $<0.001$ \\
\hline Family & $44.1 / 4.1$ & $43.0 / 5.0$ & $43.5 / 4.5$ & $45.1 / 3.9$ & $45.6 / 3.8$ & $45.4 / 3.9$ & 0.158 & 0.121 & 0.038 \\
\hline Egalitarian & $40.5 / 3.5$ & $41.6 / 3.4$ & $41.0 / 3.5$ & $42.7 / 3.0$ & $43.1 / 2.4$ & $42.9 / 2.7$ & 0.078 & $<0.001$ & $<0.001$ \\
\hline Conception & $39.4 / 3.5$ & $39.2 / 3.5$ & $39.3 / 3.5$ & $40.0 / 2.8$ & $40.8 / 2.9$ & $40.4 / 2.8$ & 0.085 & 0.031 & 0.006 \\
\hline Communication & $43.1 / 5.5$ & $42.6 / 5.1$ & $42.9 / 5.3$ & $45.6 / 4.7$ & $45.9 / 4.6$ & $45.7 / 4.6$ & 0.142 & 0.327 & 0.085 \\
\hline Conflict & $40.5 / 5.7$ & $39.3 / 5.9$ & $39.9 / 5.8$ & $42.7 / 5.3$ & $42.4 / 5.01$ & $42.5 / 5.2$ & 0.155 & 0.001 & 0.001 \\
\hline Financial & $43.0 / 4.1$ & $42.7 / 4.2$ & $42.8 / 4.12$ & $43.9 / 4.4$ & $43.7 / 4.7$ & $43.8 / 4.6$ & $<0.001$ & 0.010 & $<0.001$ \\
\hline Leisure & $40.6 / 4.6$ & $38.3 / 5.8$ & $39.4 / 5.4$ & $41.9 / 5.1$ & $42.0 / 4.7$ & $42.0 / 4.9$ & 0.136 & 0.003 & 0.002 \\
\hline Total & $421.6 / 30.4$ & $415.3 / 32.0$ & $418.5 / 31.2$ & $435.3 / 28.3$ & $437.3 / 25.8$ & $436.3 / 27.0$ & 0.009 & $<0.001$ & $<0.001$ \\
\hline
\end{tabular}

*Mann Whitney U-test. 
Table 3 The couples assessment of their relationship about three years after termination of assisted reproduction

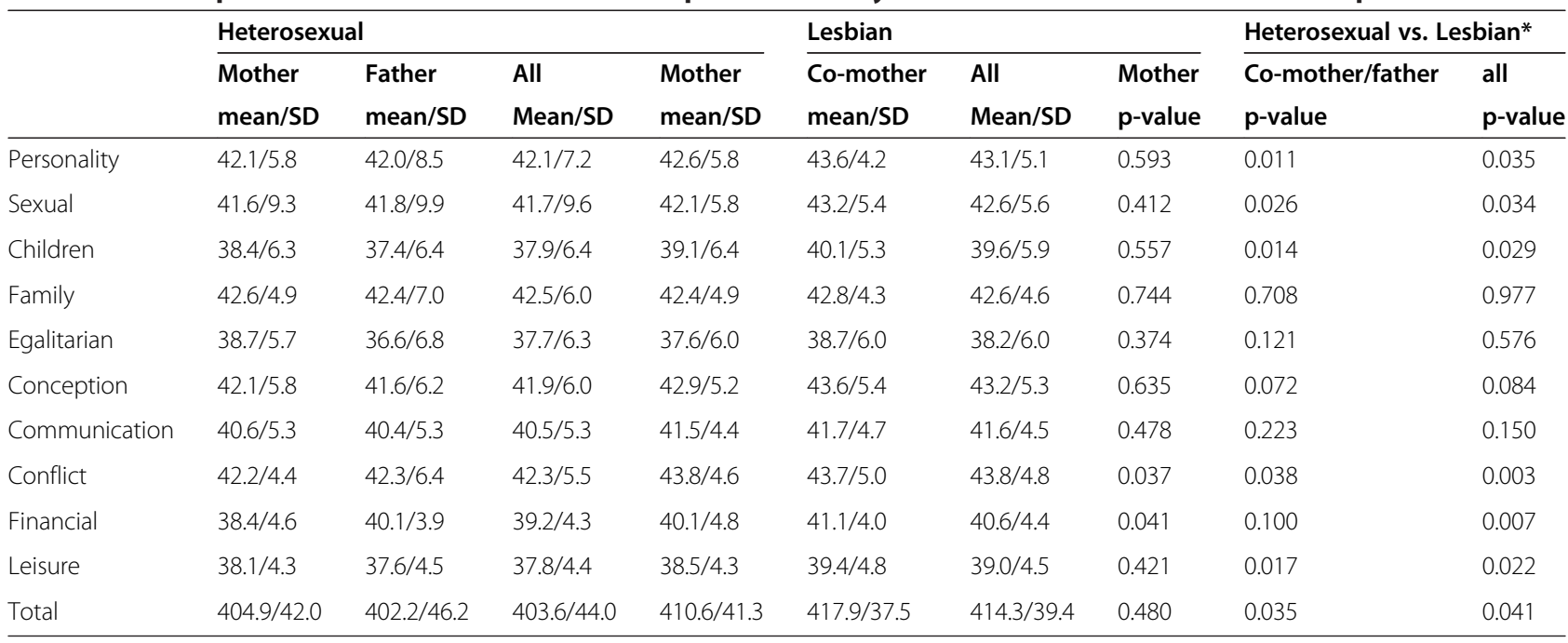

*Mann Whitney U-test.

Table 5 displays results from the analysis of couple congruence.

At T1 as well as T3, the lesbian couples had higher congruence scores than the heterosexual couples on all subareas except for Children and Financial. Testing for differences on PCA-scores between measurements before treatment and at follow-up both lesbian and heterosexual couples reported a decrease in satisfaction in all relationship dimensions, Figure 2.

Difference on the ENRICH scores within the couples for each subarea comparing measurements before treatment and three years after treatment, reported by successful and unsuccessful treatment, was measured. The treatment outcome (T3) was related to lesbian couples relationship satisfaction only in the subarea Communication, treated lesbian women $(\mathrm{p}=0.018)$ and lesbian partners $(\mathrm{p}=0.001)$ with a successful treatment reported lower satisfaction than those whose treatment did not result in a child. In the heterosexual couples however, women reported lower satisfaction with relationship after a successful treatment on a number of subareas; Egalitarian Roles $(\mathrm{p}=0.025)$, Conception of Life $(\mathrm{p}=0.038)$, Communication $(\mathrm{p}=0.001)$, Conflict Resolution $(\mathrm{p}=0.046)$ and Financial Management $(\mathrm{p}=0.045)$. Heterosexual mens perceptions were not associated by the success of the treatment.

Also an analysis of differences on the ENRICH scores on each subarea, before treatment and about three years after treatment, reported by successful or unsuccessful treatment and couple type was performed. An unsuccessful treatment was associated with lower scores from

Table 4 Test for difference on the ENRICH scores for each subscale comparing measurements before treatment and about three years after treatment/childbirth*

\begin{tabular}{|c|c|c|c|c|c|c|}
\hline & \multicolumn{2}{|c|}{ Heterosexual } & \multicolumn{2}{|l|}{ Lesbian } & \multirow{2}{*}{$\begin{array}{l}\text { Heterosexual } \\
\text { All } \\
\text { p-value }\end{array}$} & \multirow{2}{*}{$\begin{array}{l}\text { Lesbian } \\
\text { All } \\
\text { p-value }\end{array}$} \\
\hline & $\begin{array}{l}\text { Mother } \\
\text { p-value }\end{array}$ & $\begin{array}{l}\text { Father } \\
\text { p-value }\end{array}$ & $\begin{array}{l}\text { Mother } \\
\text { p-value }\end{array}$ & $\begin{array}{l}\text { Co-mother } \\
\text { p-value }\end{array}$ & & \\
\hline Personality & 0.001 & 0.912 & $<0.001$ & 0.007 & 0.150 & $<0.001$ \\
\hline Sexual & 0.145 & 0.124 & 0.117 & 0.348 & 0.034 & 0.072 \\
\hline Children & $<0.001$ & $<0.001$ & $<0.001$ & $<0.001$ & $<0.001$ & $<0.001$ \\
\hline Family & 0.002 & 0.389 & 0.054 & 0.002 & 0.009 & $<0.001$ \\
\hline Egalitarian & $<0.001$ & 0.002 & $<0.001$ & $<0.001$ & $<0.001$ & $<0.001$ \\
\hline Conception & 0.007 & 0.002 & 0.005 & 0.039 & $<0.001$ & 0.001 \\
\hline Communication & 0.127 & 0.467 & $<0.001$ & $<0.001$ & 0.123 & $<0.001$ \\
\hline Conflict & 0.001 & $<0.001$ & $<0.001$ & $<0.001$ & $<0.001$ & $<0.001$ \\
\hline Financial & 0.503 & 0.683 & 0.014 & 0.094 & 0.478 & 0.003 \\
\hline Leisure & 0.002 & 0.066 & $<0.001$ & $<0.001$ & 0.001 & $<0.001$ \\
\hline Total & $<0.001$ & 0.004 & $<0.001$ & $<0.001$ & $<0.001$ & $<0.001$ \\
\hline
\end{tabular}

*Paired sample t-test. 
Table 5 The couples assessment of their relationship according to PCA (Positive Couple Agreement) at first treatment and about three years after termination

\begin{tabular}{|c|c|c|c|c|c|c|c|}
\hline & $\begin{array}{l}\text { Heterosexual } \\
\text { mean/SD }\end{array}$ & $\begin{array}{l}\text { Lesbian } \\
\text { mean/SD }\end{array}$ & $\begin{array}{l}\text { Heterosexual vs. Lesbian* } \\
\text { p-value }\end{array}$ & & $\begin{array}{l}\text { Heterosexual } \\
\text { mean/SD }\end{array}$ & $\begin{array}{l}\text { Lesbian } \\
\text { mean/SD }\end{array}$ & $\begin{array}{l}\text { Hetero vs. Lesbian* } \\
\text { p-value }\end{array}$ \\
\hline Personality & $66.3 / 20.5$ & $80.9 / 17.0$ & $<0.001$ & Personality & $60.0 / 24.5$ & $68.2 / 23.4$ & 0.049 \\
\hline Sexual & $84.4 / 16.2$ & $88.4 / 15.4$ & 0.057 & Sexual & $64.4 / 28.2$ & $73.7 / 22.6$ & 0.054 \\
\hline Children & 74.9/17.1 & 79.6/11.0 & 0.137 & Children & $60.3 / 24.3$ & $66.8 / 18.2$ & 0.107 \\
\hline Family & 74.6/19.1 & 81.9/16.7 & 0.009 & Family & $68.1 / 21.2$ & $76.3 / 20.1$ & 0.005 \\
\hline Egalitarian & $64.3 / 16.5$ & $75.1 / 12.3$ & $<0.001$ & Egalitarian & $56.3 / 21.3$ & $64.6 / 20.1$ & 0.014 \\
\hline Conception & $34.3 / 15.1$ & $70.7 / 8.4$ & 0.004 & Conception & $57.3 / 19.0$ & $63.5 / / 18.0$ & 0.008 \\
\hline Communication & $71.9 / 22.3$ & $85.3 / 17.4$ & $<0.001$ & Communication & $59.8 / 28.3$ & $70.7 / 21.8$ & 0.024 \\
\hline Conflict & $57.5 / 22.8$ & $68.1 / 21.2$ & 0.003 & Conflict & $44.1 / 27.2$ & $54.7 / 25.4$ & 0.008 \\
\hline Financial & $71.0 / 18.3$ & $75.3 / 18.8$ & 0.119 & Financial & $66.2 / 25.2$ & $70.9 / 17.2$ & 0.568 \\
\hline Leisure & $57.9 / 21.5$ & $68.6 / 24.3$ & 0.001 & Leisure & $44.4 / 26.2$ & $52.1 / 22.1$ & 0.038 \\
\hline Total & $687.1 / 143.9$ & 773.9/118.1 & $<0.001$ & Total & $581.1 / 198.5$ & $661.6 / 165.5$ & 0.011 \\
\hline
\end{tabular}

*Mann Whitney U-test.

heterosexual men compared to lesbian partners in the subarea Communication $(p=0.031)$. Comparing lesbian and heterosexual treated women with a successful treatment, scores from lesbian treated women were higher than from heterosexual women on Conflict Resolution $(p=0.029)$ and Financial Management $(p=0.023)$. Finally, comparing lesbian partners and heterosexual men with a successful treatment, lesbian partners reported more satisfaction with Leisure activities $(\mathrm{p}=0.023)$.

Finally, we tested for differences on ENRICH and PCA scores reported by age and level of education, and differences on ENRICH scores were found amongst women with a high school degree. At T3, heterosexual women with a high school degree reported lower scores than treated lesbian women with a high school degree in the subareas Personality $(\mathrm{p}=0.003)$, Communication 0.018$)$,
Sexual $(\mathrm{p}=0.018)$, Egalitarian Roles $(\mathrm{p}=0.018)$ and Total ENRICH $(p=0.024)$, but higher than treated lesbian women on subareas Communication $(\mathrm{p}=0.018)$, Leisure $(\mathrm{p}=0.032)$ and Children $(\mathrm{p}=0.032)$.

The association of age on ENRICH scores were minor. For women, the differences that appeared were from the group aged $>30$ year. At T1 treated lesbian women had higher scores on several of subareas as in Total ENRICH (430.7 vs. $420.4 \mathrm{p}=0.001$ ). At $\mathrm{T} 3$, this association remained only in three subareas and Total ENRICH was (403.2 vs. 402.4 $\mathrm{p}=0.036$ ). Amongst the group of younger ( $\leq 30$ years) partners, at T1 lesbian partners had higher scores on some of the subareas and Total ENRICH (439.6 vs $414.4 \mathrm{p}=0.019$ ) than heterosexual men. This association did not remain at T3, Total ENRICH $(p=0.227)$.

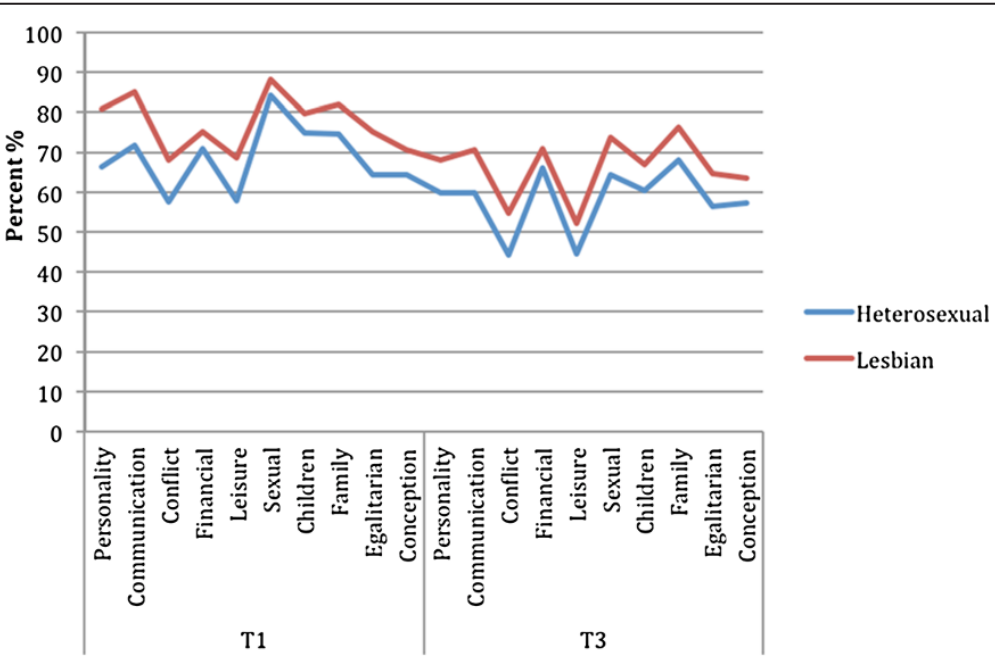

Figure 2 Couples congruence on Enrich subscales at T1 and T3. 


\section{Discussion}

\section{Main findings}

The main finding in this study was that the lesbian couples reported higher satisfaction with their relationship during the trajectories of assisted reproduction. Although there were differences in many of the ENRICH assessments, the heterosexual couples did not report a low relationship satisfaction. Both the lesbian couples and the heterosexual couples reported scores within the two best-functioning categories according to Olson \& Fowers (1993) i.e. Harmonious Couples and Vitalised Couples [30].

\section{Strength and limitations}

To date no previous studies have compared relationship satisfaction in lesbian and heterosexual couples during the time of undergoing assisted reproduction in Sweden. The data from this study are unique and contribute important knowledge to the existing research on planned lesbian families. The strengths of the study design also include the prospective longitudinal method, which allows investigation in changes over time. The couples were recruited from the whole of Sweden, at all university clinics that perform sperm donation treatment and hence the study is comprised of a wide range of couples from both rural and urban areas. Furthermore the ENRICH inventory is a well-established instrument which is frequently used in studies of couples undergoing assisted reproduction [21-23]. The large sample of 120 couples responding to questionnaires at two time points provide further strengths to the study.

However, one must bear in mind that the couples in this study are a selected group of stable couples that went to a fertility clinic to conceive. Hence, the result from this study can only be generalised to couples that undergo assisted reproduction in a clinical setting. To lesbian couples for example, there are ways to conceive outside the clinical setting, such as private arrangements with a known or stranger donor (a donor the couple found on the internet for example); an insecure and troublesome route to conception, far away from the stability and safe treatment fertility clinics offer $[14,15]$.

Due to responses from only one partner in the couple, many of the couples that participated at T1 dropped-out at T3. This means that the sample of this study is comprised of couples that are still cohabiting or married approximately three years after the commencement of treatment.

\section{Interpretation}

Both lesbian and heterosexual couples reported a decrease in relationship satisfaction compared to when they first commenced treatment. Similar to previous findings [21-23], the subarea sexual relationship was the only subarea that, jointly for the couples, did not decrease over time. Our findings suggest that, rather than being different, lesbian and heterosexual couples experiences of relationship satisfaction after assisted reproduction and childbirth are similar to each other. Previously, both Kurdek (2005) and Peplau and Fingerhut (2007) have reported more similarities than differences between samesex and heterosexual couples with regards to aspects of relationship quality and wellbeing $[1,27]$.

It has been reported that lesbian couples are more egalitarian in their roles and share household and childcare tasks differently than heterosexual couples [31]. In this study, we could not see any differences in satisfaction with egalitarian roles; all parties, lesbian treated women and partners, and heterosexual women and men experienced a decrease in egalitarian roles. Perhaps this mirrors the fact that this is a selected group of couples, highly motivated towards parenthood and with stable relationships.

Some interesting differences were found between the couples when the treatment was unsuccessful. Whilst the lesbian treated women and their partners only reported a decline in relationship satisfaction in the subarea communication, an unsuccessful treatment seemed to affect heterosexual treated women much more; several of the subareas were associated with lower scores. Maybe one explanation for this can be found in the fact that many lesbian couples when they build their family, take in turn to be the birthmother [16,32]. In this way the lesbian couples may perceive that they have another chance to have a child if the assisted reproduction treatment of one of the women in the couple is unsuccessful. For the heterosexual women the alternatives after unsuccessful IVF-treatment are limited to gamete donation, adoption or to live without children. Another suggestion to explain the influence an unsuccessful treatment had on heterosexual women s perception of relationship satisfaction is that this might be an expression of pressure by social expectations to form a traditional nuclear family, to conceive and form a family with children.

Some minor differences emerged when the treatment was successful and resulted in the birth of a child. The subareas conflict and financial revealed a significant difference between the lesbian and heterosexual treated women, and the heterosexual women reported lower satisfaction on this matter. Heterosexual men reported lower satisfaction in personality and leisure compared to lesbian partners with a successful treatment. Perhaps this can be explained by gender differences and that lesbian couples might benefit from the presence of two women in the couple. Some authors suggest that lesbian couples may be able to operate more easily in terms of equality because partners in lesbian couples create their relationships without reference to traditional roles and 
come to their relationships with a history of being socialised into the same gender roles [33]. It has also been suggested that same-sex couples may be more effective than their heterosexual counterparts in their ability to navigate conflict [34] and to work harmoniously on joint tasks [35]. Some suggest further that women are better support providers than men, and that female partners providing better support can also explain the lower level of conflict in lesbian couple [36].

\section{Conclusion}

At a three-year follow up after assisted reproduction with donated sperm, lesbian couples reported stable relationships and a high satisfaction with their relationship, also after an unsuccessful treatment. Compared to heterosexual IVF couples, lesbian couples reported higher satisfaction.

\section{Competing interests}

The authors declare that they have no competing interests.

\section{Authors contributions}

$\mathrm{CL}$, ASS and GS planned and designed the study. CL, ASS, and GS contributed to the acquisition of data. $\mathrm{CB}$ and $\mathrm{MB}$ analysed the data and MB provided statistical support throughout the working process. CB was primarily responsible for writing the paper. All authors were involved in the drafting and revising of the paper and approved the final version of the manuscript for submission.

\section{Acknowledgment}

We thank the families who participated in the study and also selected staff members at the fertility clinics at the University Hospital in Gteborg, Stockholm, Uppsala, Linkping, Malm, rebro, Ume that made significant contributions to the recruitment of participants and data collection. Merck Serono provided financial support throughout the implementation of the study. The Uppsala/rebro Regional Research Council also provided financial support. Financial support was also received from the Medical Research council of Southeast Sweden, the Swedish Research Council for Health, Working Life and Welfare, as well as from the Marianne and Marcus Wallenberg Foundation.

\section{Author details}

'Department of Women s and Children s Health, Uppsala University, S-751 85 Uppsala, Sweden. ${ }^{2}$ Neurobiology, Care Sciences and Society, Karolinska Institutet, S-141 83 Huddinge, Sweden. ${ }^{3}$ Division of Obstetrics and Gynecology, Department of Clinical and experimental Medicine, Faculty of Health and Science, Linkping University, Linkping, Sweden. ${ }^{4}$ Department of Gynecology and Obstetrics in Linkping, County Council of stergtland, Linkping, Sweden.

Received: 11 March 2014 Accepted: 17 November 2014

Published online: 12 December 2014

\section{References}

1. Peplau LA, Fingerhut AW: The close relationships of lesbians and gay men. Annu Rev Psychol 2007, 58:405 424.

2. SFS: Svensk frfattningssamling ; 2009:260

3. Riskind RG, Patterson CJ: Parenting intentions and desires among childless lesbian, gay, and heterosexual individuals. J Fam Psychol 2010, 24(1):78 81 .

4. Werner C, Westerstahl A: Donor insemination and parenting: concerns and strategies of lesbian couples. A review of international studies. Acta Obstet Gynecol Scand 2008, 87(7):697 701.

5. Nordqvist, P: Procreation matters, swedish lesbian mother s narratives of planning parenthood through donor insemination and IVF.
Dissertation MA of Womens studies. Centre for Women s Studies University of York, UK; 2006.

6. Bos HM, van Balen F, van Den Boom DC: Experience of parenthood, couple relationship, social support, and child-rearing goals in planned lesbian mother families. J Child Psychol Psychiatry 2004, 45(4):755 764.

7. Nelson KZ: Mot alla odds. Malm: Liber; 2007.

8. Lewis J: The rating of prenatal marital competence. Fam Proc 1988, 27:149 165

9. Ahlborg T, Strandmark M: The baby was the focus of attention first-time parents experiences of their intimate relationship. Scand J Caring Sci 2001, 15(4):318 325.

10. Kurdek L: Are gay and lesbian cohabiting couples really different from heterosexual married couples? J Marriage Fam 2004, 66(4):880 900

11. Ducharme JK, Kollar MM: Does the marriage benefit extend to same-sex union?: Evidence from a sample of married lesbian couples in Massachusetts. J Homosex 2012, 59(4):580 591.

12. Solomon R: Balsam: pioneersin partnership: lesbian and gay male couples in civil unions compared with those not in civil unions and married heterosexual siblings. J Fam Psychol 2004, 18:275 286.

13. Borneskog C, Skoog Svanberg A, Lampic C, Sydsjo G: Relationship quality in lesbian and heterosexual couples undergoing treatment with assisted reproduction. Hum Reprod 2012, 27(3):779 786.

14. Nordqvist P: Choreographies of sperm donations: dilemmas of intimacy in lesbian couple donor conception. Soc Sci Med 2011, 73(11):1661 1668.

15. Nordqvist $P$ : Dealing with sperm: comparing lesbians clinical and non-clinical donor conception processes. Sociol Health Illn 2011, 33(1):114 129.

16. Nordqvist P: Origins and originators: lesbian couples negotiating parental identities and sperm donor conception. Cult Health Sex 2012, 14(3):297 311

17. Verhaak CM, Smeenk JM, Evers AW, Kremer JA, Kraaimaat FW, Braat DD: Women s emotional adjustment to IVF: a systematic review of 25 years of research. Hum Reprod Update 2007, 13(1):27 36.

18. Gameiro S, Boivin J, Peronace L, Verhaak CM: Why do patients discontinue fertility treatment? A systematic review of reasons and predictors of discontinuation in fertility treatment. Hum Reprod Update 2012, 18(6):652 669

19. Drosdzol A, Skrzypulec V: Quality of life and sexual functioning of Polish infertile couples. Eur J Contracept Reprod Health Care 2008, 13(3):271 281.

20. Chachamovich J, Chachamovich E, Fleck MP, Cordova FP, Knauth D, Passos $\mathrm{E}$ : Congruence of quality of life among infertile men and women: findings from a couple-based study. Hum Reprod 2009, 24(9):2151 2157.

21. Sydsjo G, Svanberg AS, Lampic C, Jablonowska B: Relationships in IVF couples 20 years after treatment. Hum Reprod 2011, 26(7):1836 1842

22. Sydsj G, Ekholm K, Wadsby M, Kjellberg S, Sydsj A: Relationships in couples after failed IVF treatment: a prospective follow-up study. Hum Reprod 2005, 20(7):1952 1957.

23. Sydsj G, Wadsby M, Kjellberg S, Sydsj A: Relationships and parenthood in couples after assisted reproduction and in spontaneous primiparous couples: a prospective long-term follow-up study. Hum Reprod 2002, 17(12):3242 3250 .

24. Gameiro S, Nazare B, Fonseca A, Moura-Ramos M, Canavarro MC: Changes in marital congruence and quality of life across the transition to parenthood in couples who conceived spontaneously or with assisted reproductive technologies. Fertil Steril 2011, 96(6):1457 1462.

25. Sandfort TG, Bakker F, Schellevis FG, Vanwesenbeeck I: Sexual orientation and mental and physical health status: findings from a Dutch population survey. Am J Public Health 2006, 96(6):1119 1125.

26. Tjepkema M: Health care use among gay, lesbian and bisexual Canadians. Health Rep 2008, 19(1):53 64.

27. Kurdek L: What do we know about gay and lesbian couples? Curr Dir Psycholsci 2005, 14:251 254.

28. Fournier DOD, Druckman J: Assessing marital and premarital relationships: the PREPARE/ENRICH inventories. In Marriage and Family Assessment. Edited by Filsinger EE. Newsbury, CA: Sage Publications; 1983:229 250

29. Wadsby M: Evaluation of the Swedish version of the ENRICH Marital Inventory. Nord J Psychiatry 1998, 52(5):379 387.

30. Olson DFB: Five types of marriage: an empirical typology based on ENRICH. Fam J 1993, 1(3):196 207.

31. Bos H, van Balen F: Children of the new reproductive technologies: social and genetic parenthood. Patient Educ Couns 2010, 81(3):429 435. 
32. Borneskog C, Sydsjo G, Lampic C, Bladh M, Svanberg A: Symptoms of anxiety and depression in lesbian couples treated with donated sperm: a descriptive study. BJOG 2013, 120(7):839 846.

33. Kurdek LA, Kennedy C: Differences between couples who end their marriage by fault or no-fault legal procedures. J Fam Psychol 2001, 15(2):241 253

34. Gottman JM, Levenson RW, Swanson C, Swanson K, Tyson R, Yoshimoto D: Observing gay, lesbian and heterosexual couples relationships: mathematical modeling of conflict interaction. J Homosex 2003, 45(1):65 91

35. Roisman Gl, Clausell E, Holland A, Fortuna K, Elieff C: Adult romantic relationships as contexts of human development: a multimethod comparison of same-sex couples with opposite-sex dating, engaged, and married dyads. Dev Psychol 2008, 44(1):91 101.

36. Meuwly NFB, Davila J, Nunez D, Bodenmann G: Relationship quality among Swiss women opposite-sex versus same-sex romantic relationships. Swiss J Psychol 2013, 72:229 233.

doi:10.1186/s12905-014-0154-1

Cite this article as: Borneskog et al:: Relationship satisfaction in lesbian and heterosexual couples before and after assisted reproduction: a longitudinal follow-up study. BMC Women's Health 2014 14:154.

\section{Submit your next manuscript to BioMed Central and take full advantage of:}

$\otimes$ Convenient online submission

$\otimes$ Thorough peer review

$\otimes$ No space constraints or color $\bowtie$ gure charges

$\bigotimes$ Immediate publication on acceptance

Q Inclusion in PubMed, CAS, Scopus and Google Scholar

$\otimes$ Research which is freely available for redistribution 